\title{
Prilagoditvene spretnosti
}

\author{
Staša Stropnik* in Jana Kodrič \\ Pediatrična klinika, KO za otroško, mladostniško in razvojno nevrologijo
}

Povzetek: Prilagoditvene spretnosti predstavljajo konceptualne, socialne in praktične spretnosti, ki se jih ljudje naučimo, da lahko delujemo v vsakodnevnem življenju. Vključujejo posameznikovo sposobnost zadovoljevanja vsakodnevnih potreb ob upoštevanju zahtev okolja. Dobro razvite prilagoditvene spretnosti se kažejo pri posameznikovi neodvisnosti v različnih okoljih, nizke prilagoditvene spretnosti pa se povezujejo s posameznikovo nesamostojnostjo in večjo potrebo po nadzoru in pomoči pri vsakodnevnih nalogah. Pogosto se ocenjevanje prilagoditvenih spretnosti povezuje $\mathrm{z}$ ocenjevanjem motnje $\mathrm{v}$ duševnem razvoju, saj diagnoza motnja v duševnem razvoju poleg nižjih dosežkov pri standardiziranih preizkusih spoznavnih sposobnosti vključuje tudi pomembne primanjkljaje prilagoditvenih spretnostih. Ocenjevanje prilagoditvenih spretnosti je del standardne ocenjevalne baterije pri otrocih in odraslih, ki imajo različne težave, motnje ali zmanjšane zmožnosti, ki vplivajo na njihovo vsakodnevno funkcioniranje. V prispevku so predstavljeni tudi psihometrični pripomočki, ki se najpogosteje uporabljajo za ocenjevanje prilagoditvenih spretnosti in značilnosti prilagoditvenih spretnosti pri posameznih kliničnih skupinah.

Ključne besede: prilagoditvene spretnosti, motnje v duševnem razvoju, ocenjevanje

\section{Adaptive skills}

Staša Stropnik and Jana Kodrič University Children's Hospital, Department of Child, Adolescent and Developmental Neurology, Slovenia

\begin{abstract}
Adaptive skills are defined as a collection of conceptual, social and practical skills that are learned by people in order to function in their everyday lives. They include an individual's ability to adapt to and manage her or his surroundings to effectively function and meet social or community expectations. Good adaptive skills promote individual's independence in different environments, whereas poorly developed adaptive skills are connected to individual's dependency and with greater need for control and help with everyday tasks. Assessment of adaptive skills is often connected to assessment of intellectual disability, due to the reason that the diagnosis of intellectual disability includes lower levels of achievements on standardized tests of intellectual abilities as well as important deficits in adaptive skills. Assessment of adaptive behavior is a part of standard assessment battery with children and adults with different problems, disorders or disabilities that affect their everyday functioning. This contribution also presents psychometric tools most regularly used for assessment of adaptive skills and characteristics of adaptive skills with individual clinical groups.
\end{abstract}

Key words: adaptive skills, intellectual disabilities, assessment

\footnotetext{
"Naslov/Address: Staša Stropnik, Pediatrična klinika Ljubljana, Bohoričeva 20, Ljubljana, e-mail: stasastropnik@gmail.com ali stasa. stropnik@kclj.si

Članek je licenciran pod pogoji Creative Commons Attribution 4.0 licence. / The article is licensed under a Creative Commons Attribution 4.0 International License.
} 


\section{Opredelitev prilagoditvenih spretnosti}

Prilagoditvene spretnosti (ang. adaptive skills) ${ }^{1}$ so naučena vedenja, ki vključujejo posameznikovo zmožnost prilagoditve in obvladovanja okolja, z namenom učinkovitega delovanja v skladu s socialnimi pričakovanji (Harrison in Oakland, 2008). Prilagoditvene spretnosti pri malčkih so na primer govor, hoja in hranjenje po žlici, pri starejših otrocih so to na primer prečkanje ceste, obisk trgovine in upoštevanje različnih pravil pri interakciji $\mathrm{z}$ drugimi ljudmi (npr. kdaj reči hvala in kdaj prosim), pri odraslih pa na primer redno prihajanje $\mathrm{v}$ službo, samostojno odločanje o stvareh in sklepanje prijateljstev. Sparrow, Cicchetti in Balla (2005) poudarjajo, da gre pri prilagoditvenih spretnostih za značilno vedenje posameznika in ne za sposobnost. Sposobnost je sicer nujni pogoj za učinkovito opravljanje dnevnih dejavnosti, vendar posameznikove prilagoditvene spretnosti niso učinkovite, če niso uporabljene takrat, ko je to potrebno (Bornstein, Giusti, Leach in Venuti, 2005).

V literaturi se pojavlja veliko različnih opredelitev prilagoditvenih spretnosti. Čeprav med njimi obstajajo manjšerazlike,jevsem skupen poudarekna posameznikovi neodvisnosti in socialni odgovornosti (povzeto po Reva in Bardos, 2010). Posameznikovo prilagajanje na zahteve okolja je bistveno za njegov razvoj (Reva in Bardos, 2010). Prilagoditvene spretnosti so namreč ključnega pomena za uspešno rast in razvoj vseh organizmov, ki se razvijajo v interakciji $\mathrm{z}$ okoljem in $\mathrm{v}$ določenem socialnem kontekstu (Bornstein idr., 2005).

Ameriško združenje za motnje v duševnem razvoju in razvojne motnje (American Association on Intellectual and DevelopmentalDisabilities [AAIDD],2012)prilagoditvene spretnosti opredeljuje kot skupek konceptualnih, socialnih in praktičnih spretnosti, ki se jih ljudje naučimo, da bi lahko funkcionirali v vsakodnevnem življenju. Naučene spretnosti posamezniku omogočajo učinkovito delovanje pri dnevnih aktivnostih in samostojnost v vsakodnevnem funkcioniranju (Sparrow idr., 2005).

Pomembne omejitve pri prilagoditvenih spretnostih učinkujejo na posameznikovo vsakdanje življenje in njegovo zmožnost odzivanja $\mathrm{v}$ določenih situacijah ali okolju (AAIDD, 2012). AAIDD zato posebej izpostavlja pomen izboljšanja posameznih prilagoditvenih spretnosti (s pomočjo vodenega učenja in posebnih metod ojačevanja vedenja) in ne le njihovega ocenjevanja (Harman, SmithBonahue in Oakland, 2010).

Dobro razvite prilagoditvene spretnosti se kažejo pri posameznikovi neodvisnosti v različnih okoljih - doma, v šoli in družbi. Nizke prilagoditvene spretnosti pa se povezujejo s posameznikovo nesamostojnostjo in večjo

\footnotetext{
${ }^{1}$ Za opisovanje naučenih vedenj oziroma spretnosti, s katerimi opisujemo posameznikovo neodvisnost in samostojnost $\mathrm{v}$ vsakdanjem življenju, se v angleščini uporabljata izraza adaptive behavior ali adaptive skills.
}

potrebo po nadzoru in pomoči pri vsakodnevnih nalogah (Harrison in Oakland, 2008).

\section{Dejavniki, povezani s prilagoditvenimi spretnostmi}

Posameznikove prilagoditvene spretnosti se lahko spreminjajo glede na situacijo in čas, glede na različne zahteve, pričakovanja in podporo v okolju (BorthwickDuffy, 2006). Dejavniki, ki jih moramo upoštevati pri ocenjevanju in preučevanju prilagoditvenih spretnosti, so kultura, okolje in starost.

\section{Kultura}

Večina opredelitev prilagoditvenih spretnosti poudarja učinek kulturnih pričakovanj nanje (Borthwick-Duffy, 2006). V nasprotju s preizkusi spoznavnih sposobnosti, ki naj bi bili neodvisni od kulturnih in kontekstualnih dejavnikov, se nekateri opisi na lestvicah prilagoditvenih spretnosti namenoma nanašajo na posameznikovo vedenje, ki je odraz kulturnih norm, saj so prilagoditvene spretnosti že po opredelitvi odvisne od zahtev okolja, v katerem posameznik živi. Tudi številne študije (npr. Taverna, Bornstein, Putnick in Axia, 2011) poročajo o pomembnih razlikah $\mathrm{v}$ prilagoditvenih spretnostih pri posameznikih v različnih kulturnih okoljih. Ker je nemogoče oblikovati standardizacijski vzorec, ki bi zajemal vse kulturne skupine, sta Tassé in Craig (1999) predlagala oblikovanje kulturnospecifičnih ocenjevalnih pripomočkov. Ker takih preizkusov večina držav nima, je nujna dobra klinična presoja pri interpretaciji rezultatov, ki jih pridobimo s tujimi lestvicami prilagoditvenih spretnosti.

\section{Okolje}

Ocena prilagoditvenih spretnosti je odvisna od specifičnega okolja, v katerem posameznik preživlja svoj čas. Posameznikovo vedenje moramo namreč vedno ocenjevati v skladu s pričakovanji okolja, v katerem preživi večino svojega časa - če je na primer otrok vključen $v$ ustanovo, znotraj katere nima stika z vrstniki, ki nimajo težav v razvoju, moramo njegovo vedenje oceniti v skladu s pričakovanji, ki jih ima ustanova do svojih varovancev (Borthwick-Duffy, 2006). V nekaterih primerih se posameznik bolje prilagodi na eno okolje (npr. šolo) kot na drugo (npr. dom), odvisno od zahtev in podpore, ki jo ima v določenem okolju.

\section{Starost}

Starost je ključni dejavnik za izbiro ocenjevalnega pripomočka in za opisovanje prilagoditvenih spretnosti posameznika. Zahteve in pričakovanja okolja se s starostjo posameznika spreminjajo, postajajo vedno bolj kompleksne in številčnejše (Borthwick-Duffy, 2006). Sparrow in sodelavci (2005) pravijo, da so prilagoditvene 
spretnosti razvojno pogojene, kar pomeni, da otrok pridobiva spretnosti s starostjo in izkušnjami. Pri večini ljudi je prilagoditvenih spretnosti s starostjo vedno več, postajajo tudi kompleksnejše. Za mlajše otroke je tako na primer pomembno, da se znajo obleči in da se razumejo s prijatelji pri igri, za odrasle pa je bistvenega pomena na primer to, da obdržijo službo in odgovorno ravnajo $\mathrm{z}$ denarjem. Kljub temu da obstajajo neke razvojne smernice o tem, kdaj naj bi se določena prilagoditvena spretnost pojavila, pa je pojavnost prilagoditvenih spretnosti precej kulturno pogojena in določena s prepričanjem ljudi o tem, česa so otroci sposobni pri določeni starosti. Za usvojitev določenih prilagoditvenih spretnosti je nujna tudi fizična zrelost otroka in že usvojena nekatera druga vedenja - preden lahko na primer otrok samostojno je, se mora naučiti držati žlico, razvita mora biti usklajenost med gibi rok in ust, da lahko nese hrano v usta itd. (Sparrow idr., 2005).

\section{Področja prilagoditvenih spretnosti}

$\mathrm{V}$ opredelitvi prilagoditvenih spretnosti, ki jo je leta 2002 podala AAIDD (Luckasson idr. 2002), so predstavljena tri področja prilagoditvenih spretnosti, ki se izražajo v konceptualnih, praktičnih in socialnih spretnostih. Borthwick-Duffy (2006) in Harman in sodelavci (2010) posamezna področja prilagoditvenih spretnosti opredeljujejo kot:

- praktične spretnosti so spretnosti, ki omogočajo posameznikuneodvisnostvvsakodnevnemživljenju, in vključujejo področja skrbi zase, življenja doma/v šoli, širšem okolju, zdravje in varnost ter delo;

- socialne spretnosti obsegajo posameznikovo odgovornost $\mathrm{V}$ socialnih situacijah - izpolniti socialna pričakovanja drugih, biti spreten $\mathrm{V}$ socialnih situacijah - in vključujejo področji socialnih spretnosti in spretnosti pri prostočasnih dejavnostih;

- konceptualne spretnosti opisujejo predvsem spoznavne in akademske spretnosti ter komunikacijo, vključujejo pa področja komunikacije, funkcionalnih (pred)akademskih veščin in samonadzora.

AAIDD (1992) in Diagnostični in statistični priročnik dušenih motenj, četrta izdaja (Diagnostic and Statistical Manual of Mental Disorders [DSM-IV], 1994), navajata deset specifičnih področij prilagoditvenih spretnosti: komunikacija, širše okolje, funkcionalne (pred)akademske spretnosti, življenje doma/v šoli, zdravje in varnost, prosti čas, skrb zase, samonadzor, socialne spretnosti in delo. Nekateri standardizirani pripomočki za ocenjevanje prilagoditvenih spretnosti pri otrocih med področja prilagoditvenih spretnosti uvrščajo tudi gibanje, ki nadomesti področje dela, ocenjevanega pri odraslih, ki so zaposleni za polni delovni čas ali del delovnega časa.

\section{Teoretična izhodišča prilagoditvenih spretnosti}

Prilagoditvene spretnosti vključujejo posameznikovo sposobnost zadovoljevanja vsakodnevnih potreb ob upoštevanju zahtev okolja (Harman idr., 2010). K razumevanju razvoja prilagoditvenih spretnosti $\mathrm{V}$ zgodnjem otroštvu najbolj prispevata dve pomembni teoriji zgodnjega razvoja: teorija navezanosti in sinaktivna teorija razvoja (Harman in Smith-Bonahue, 2010).

Teorija navezanosti opredeljuje navezanost kot vrojeno težnjo otroka, da vzpostavi vez s staršem oziroma skrbnikom (povzeto po Harman in Smith-Bonahue, 2010). Poudarja pomen socializacije, ki je opredeljena kot proces, v katerem posameznik s prirojenimi vedenjskimi potenciali razvije resnična družbeno zaželena vedenja (Child, 1954), za preživetje in prilagoditev. Socializacijo lahko otrok izpelje le s pomočjo socialnih prilagoditvenih spretnosti - v socializaciji mora biti posameznik na primer najprej sposoben socialne interakcije, šele nato se lahko odziva na potrebe drugih. Spretnosti, ki so potrebne za vzpostavitev navezanosti, so torej med najpomembnejšimi prilagoditvenimi spretnostmi, ki jih mora dojenček razviti.

$\mathrm{V}$ okviru teorije navezanosti se pri ocenjevanju prilagoditvenih spretnosti pri dojenčku in malčku sprašujemo o tem, kaj otrok naredi, da vzpostavi in vzdržuje navezanost. Večina otrok ima prirojena vedenja, ki jim pomagajo pri vzpostavljanju, razvoju in vzdrževanju navezanosti. Zdrav novorojenček je na primer sposoben sesanja, oklepanja, jokanja in nasmihanja, vsa ta vedenja pa mu pomagajo pri vzpostavljanju in oblikovanju navezanosti (Ainsworth in Bowlby, 1991). Tako se novorojenček na primer pomiri, ko je v maminem naročju, in joka, ko mama zapusti prostor, nasmehne se, ko se mu približa znan obraz ...

Sinaktivna teorija razvoja, tako kot teorija navezanosti, domneva, da morajo biti ob rojstvu prisotna nekatera prirojena vedenja, ki otroku omogočijo razvoj prilagoditvenih spretnosti. Sinaktivna teorija razvoja se osredotoča na dojenčkovo zmožnost odzivanja na okolje (Als, Butler, Kosta in McAnulty, 2005). Dojenčkova prva naloga je prilagoditev na življenje zunaj maternice in razvoj nevrološko-vedenjskih kompetenc. Pridobiti mora nadzor nad svojim fiziološkim sistemom, vključno $z$ dihanjem, bitjem srca in telesno temperaturo. Novorojenčkova naloga je organizacija in diferenciacija gibalnega sistema. Naučiti se mora obvladovati obseg, mehkobo in kompleksnost lastnega gibanja (Harman in Smith-Bonahue, 2010). Novorojenček postopoma pridobiva nadzor nad stanjem budnosti (npr. globoko spanje, dremež, budnost ...), kar doseže prav z razvojem prilagoditvenih spretnosti. Po sinaktivni teoriji obstaja pet podsistemov, ki vplivajo na otrokovo interakcijo z okoljem (Als idr., 2005): avtonomni sistem (vzorec dihanja, spremembe barve, gibi), gibalni sistem (drža, tonus in gibi), sistem organizacije stanj (stanja zavesti), sistem pozornosti in interakcije (sposobnost 
Tabela 1. Opis in primeri opisov posameznih področij prilagoditvenih spretnosti (prirejeno po: Ditterline in Oakland, 2009; Harrison in Oakland, 2008)

\begin{tabular}{|c|c|c|}
\hline $\begin{array}{l}\text { Področje } \\
\text { prilagoditvenih } \\
\text { spretnosti }\end{array}$ & Opis & Primer opisa \\
\hline Komunikacija & $\begin{array}{l}\text { Govorne spretnosti, spretnosti poslušanja } \\
\text { in jezikovne spretnosti, ki jih posameznik } \\
\text { potrebuje za komuniciranje z drugimi; } \\
\text { vključuje besednjak, odziv na vprašanje, } \\
\text { spretnosti pogovarjanja, spretnosti nebesedne } \\
\text { komunikacije ... }\end{array}$ & $\begin{array}{l}\text { Privzdigne glas, da bi pritegnil pozornost. } \\
\text { Primerno konča pogovor. } \\
\text { Sledi skupinskemu pogovoru tako dolgo, } \\
\text { dokler traja. }\end{array}$ \\
\hline Širše okolje & $\begin{array}{l}\text { Spretnosti, potrebne za funkcioniranje in } \\
\text { primerno vedenje v širšem okolju; vključuje } \\
\text { zanimanje za aktivnosti zunaj doma, } \\
\text { prepoznavanje različnih objektov (npr. } \\
\text { policijska postaja, šola, trgovina) ... }\end{array}$ & $\begin{array}{l}\text { V neposredni okolici prepozna dom. } \\
\text { Sam si pripravi prtljago za dvodnevni izlet. } \\
\text { Č je treba, pred nakupom prosi prodajalko } \\
\text { za informacije o izdelku. }\end{array}$ \\
\hline $\begin{array}{l}\text { Funkcionalne } \\
\text { (pred)akademske } \\
\text { spretnosti }\end{array}$ & $\begin{array}{l}\text { Osnovne (pred)akademske spretnosti, ki } \\
\text { predstavljajo osnovo za branje, pisanje, } \\
\text { računanje in druge veščine, ki jih posameznik } \\
\text { potrebuje za vsakodnevno neodvisno } \\
\text { funkcioniranje; vključuje prepoznavo črk, štetje, } \\
\text { risanje preprostih oblik ... }\end{array}$ & $\begin{array}{l}\text { Ko riše po papirju, drži voščenko ali svinčnik } \\
\text { s konico navzdol. } \\
\text { Prebere svoje ime, napisano s tiskanimi } \\
\text { črkami. } \\
\text { Uporabi slovar ali enciklopedijo, da bi našel } \\
\text { potrebno informacijo. }\end{array}$ \\
\hline $\begin{array}{l}\text { Življenje doma/v } \\
\text { šoli* }\end{array}$ & $\begin{array}{l}\text { Spretnosti, potrebne za osnovno skrb za dom } \\
\text { ali okolico oz. za razred; vključujejo čiščenje, } \\
\text { pospravljanje, pomoč pri hišnih opravilih, skrb } \\
\text { za osebno lastnino ... }\end{array}$ & $\begin{array}{l}\text { Prižge in ugasne televizor. } \\
\text { Svoje stvari, igrače, igre ima čiste in urejene. } \\
\text { Za pranje perila uporabi pralni stroj. }\end{array}$ \\
\hline Zdravje in varnost & $\begin{array}{l}\text { Spretnosti, potrebne za zaščito zdravja in za } \\
\text { odziv na bolezen ali poškodbo; vključujejo } \\
\text { upoštevanje varnostnih predpisov, uporabo } \\
\text { zdravil, previdnost, varovanje pred fizično } \\
\text { nevarnostjo ... }\end{array}$ & $\begin{array}{l}\text { Umazanih stvari ne daje v usta. } \\
\text { S škarjami ravna previdno. } \\
\text { Sam vzame predpisano zdravilo. }\end{array}$ \\
\hline Prosti čas & $\begin{array}{l}\text { Spretnosti, potrebne za vključitev in načrtovanje } \\
\text { prostočasnih/rekreativnih dejavnosti; } \\
\text { vključujejo igro z drugimi, igro z igračami, } \\
\text { rekreacija doma/zunaj, upoštevanje pravil igre } \\
\text {.. }\end{array}$ & $\begin{array}{l}\text { Najmanj eno minute se igra } \mathrm{z} \text { eno igračo ali } \\
\text { drugo stvarjo. } \\
\text { Upošteva pravila družabnih iger. } \\
\text { Vnaprej rezervira vstopnice za koncert, kino } \\
\text { ali športni dogodek. }\end{array}$ \\
\hline Skrb zase & $\begin{array}{l}\text { Spretnosti, potrebne za skrb zase; vključujejo } \\
\text { hranjenje, oblačenje, kopanje, uporabo } \\
\text { stranišča, skrb za higieno ... }\end{array}$ & $\begin{array}{l}\text { Drži kozarec in pije. } \\
\text { Zaveže si vezalke na čevljih. } \\
\text { Gre k frizerju. }\end{array}$ \\
\hline Samonadzor & $\begin{array}{l}\text { Spretnosti, potrebne za samostojnost, } \\
\text { odgovornost in samonadzor; vključujejo } \\
\text { odločanje v zvezi s hrano in oblačenjem, začeti } \\
\text { in dokončati dejavnost, slediti dnevni rutini, } \\
\text { upoštevati navodila ... }\end{array}$ & $\begin{array}{l}\text { Vsaj eno minuto mirno sedi, ne da bi zahteval } \\
\text { pozornost. } \\
\text { Pri težkih nalogah vztraja, ne obupa in } \\
\text { odneha. } \\
\text { Šolo oz. delo postavi pred prostočasne } \\
\text { dejavnosti. }\end{array}$ \\
\hline Socializacija & $\begin{array}{l}\text { Spretnosti, potrebne za socialno interakcijo; } \\
\text { vključujejo izražanje in prepoznavanje čustev, } \\
\text { sklepanje prijateljstev, pomoč drugim ... }\end{array}$ & $\begin{array}{l}\text { Ko vidi starše, se nasmeje. } \\
\text { Opraviči se, če je koga prizadel. } \\
\text { Pove, ko je vesel, žalosten, prestrašen ali } \\
\text { jezen. }\end{array}$ \\
\hline Delo & $\begin{array}{l}\text { Spretnosti, potrebne, da posameznik obdrži } \\
\text { službo in v njej funkcionira (za polni ali } \\
\text { polovični delovni čas); vključuje izpolnjevanje } \\
\text { delovnih nalog, delo pod nadzorom, upoštevanje } \\
\text { urnika dela ... }\end{array}$ & $\begin{array}{l}\text { Delovne naloge opravi ob pričakovanem } \\
\text { času. } \\
\text { Redno prihaja na delo. } \\
\text { Kadar je treba, pred začetkom dela vpraša za } \\
\text { navodila. }\end{array}$ \\
\hline
\end{tabular}

*Če raven prilagoditvenih spretnosti ocenjujejo starši, se ocenjevanje spretnosti nanaša na domače okolje, če pa jih ocenjujejo vzgojitelji/ učitelji, se ocenjevanje spretnosti nanaša na šolsko okolje. 
organizma, da preide $\mathrm{v}$ stanje budnosti, pozornosti) in sistem samouravnavanja čustvenih stanj in vedenja (strategije, ki jih otrok uporablja, da vzdržuje ravnotežje oz. sposobnost, da se ob porušeni stabilnosti vrne v stanje sproščenosti in relativne stabilnosti).

\section{Prilagoditvene spretnosti pri osebah z nekaterimi razvojnimi motnjami}

\section{Prilagoditvene spretnosti pri posameznikih z motnjo $v$ duševnem razvoju ${ }^{2}$}

Vsi trije svetovno priznani klasifikacijski sistemi, ki so trenutno v uporabi, Diagnostični in statistični priročnik dušenih motenj, četrta izdaja (Diagnostic and Statistical Manual of Mental Disorders [DSM-IV], 1994), Mednarodna klasifikacija bolezni, deseta izdaja (MKB10, 1995), in AAIDD (Schalock idr., 2010) v opredelitev motnje v duševnem razvoju vključujejo tako primanjkljaje v spoznavnem delovanju kot tudi pomembne primanjkljaje v prilagoditvenih spretnostih.

V DSM-IV (1994) je poudarjeno, da primanjkljaji V splošnih spoznavnih sposobnostih učinkujejo na posameznikovo delovanje na več področjih vsakodnevnega življenja, kot so na primer sporazumevanje, vključenost v družbo, učinkovitost na delu in doma, samostojnost doma in v širši družbi. Otroci z nižjimi spoznavnimi sposobnostmi dosegajo nižje rezultate pri merah prilagoditvenih spretnosti v primerjavi $\mathrm{z}$ referenčno skupino. Diagnoza motnja $\mathrm{v}$ duševnem razvoju poleg nižjih dosežkov pri standardiziranih preizkusih spoznavnih sposobnosti vključuje tudi pomembne primanjkljaje prilagoditvenih spretnosti.

AAIDD je prilagoditvene spretnosti vključila v opredelitev motnje $\mathrm{v}$ duševnem razvoju že leta 1959 (Allen-Meares, 2008), leta 1992 pa je v opredelitvi motnje v duševnem razvoju prilagoditvenim spretnostim

\footnotetext{
${ }^{2}$ Značilnosti oseb, ki jih v slovenščini opisujemo z izrazom motnja $\mathrm{v}$ duševnem razvoju, je $\mathrm{v}$ angleščini do leta 2007 opisoval izraz mental retardation, od leta 2007 pa se namesto njega uporablja izraz intellectual disability (Kodrič, 2010). Izraz disability $\mathrm{v}$ slovenščini prevajamo kot zmanjšane zmožnosti, kar je krovni izraz za okvare, omejitve dejavnosti in omejitve sodelovanja. Označuje negativne vidike interakcije med posameznikom (njegovim zdravstvenim stanjem) in spremljajočimi (okoljskimi in osebnimi) dejavniki tega posameznika (Mednarodna klasifikacija funkcioniranja, zmanjšane zmožnosti in zdravja-verzija za otroke in mladostnike, 2008). Ustreznejši prevodi izraza intellectual disability bi bili znižane intelektualne (spoznavne) sposobnosti ali intelektualna (spoznavna) manjzmožnost, ki večinoma odražajo pomen izvornega poimenovanja. Izraz motnja $\mathrm{v}$ duševnem razvoju namreč napeljuje na motnjo posameznikovega duševnega delovanja $v$ celoti, pogosto pa tudi na duševne motnje v smislju psihiatričnih motenj. V tem prispevku sva se avtorici odločili za dosledno uporabo izraza motnja v duševnem razvoju zaradi njegove vsesplošne uporabe $\mathrm{v}$ slovenskem prostoru, hkrati pa opozarjava na potrebo po zamenjavi z vsebinsko ustreznejšim prevodom.
}

pripisala večji pomen kot $\mathrm{v}$ predhodnih opredelitvah: "Motnja v duševnem razvoju predstavlja znatno omejenost posameznikovega funkcioniranja. Zanjo je značilno pomembno podpovprečno spoznavno delovanje, ob katerem so sočasno prisotne tudi omejitve na dveh ali več od naštetih področjih prilagoditvenih spretnosti: komunikacija, skrb zase, življenje doma, socialne veščine, širše okolje, samonadzor, zdravje in varnost, šolske veščine, prosti čas in delo. Motnja v duševnem razvoju se pojavi pred 18. letom starosti" (AAIDD, 1992, str. 1).

V najnovejši opredelitvi motnje $v$ duševnem razvoju pa AAIDD poudarja širše domene prilagoditvenih spretnosti: 'Motnja V duševnem razvoju pomeni pomembne omejitve posameznikovega spoznavnega funkcioniranja in prilagoditvenih spretnosti, ki predstavljajo številne konceptualne, socialne in praktične spretnosti. Motnja v duševnem razvoju se pojavi pred 18. letom" (AAIDD, 2012).

Harrison in Boan (2000) predvidevata, da gre pri prilagoditvenih spretnostih in inteligentnosti za dva ločena, vendar med seboj povezana konstrukta, in sicer navajata tri razloge: inteligentnost se nanaša na miselni proces, prilagoditvene spretnosti pa na vsakdanje vedenje; pri ocenjevanju inteligentnosti skušamo oceniti zgornjo mejo posameznikove sposobnosti, medtem ko pri prilagoditvenih spretnostih ocenjujemo običajno vedenje posameznika; lestvice inteligentnosti predvidevajo stabilnost posameznikovega rezultata, medtem ko lestvice prilagoditvenih spretnosti predvidevajo spremembo glede na različna okolja, zahteve ... Večina raziskav ugotavlja zmerno $(r=0,40-0,60)$ povezanost med spoznavnimi sposobnostmi in prilagoditvenimi spretnostmi (npr. Keith, Fehrmann, Harrison in Pottenbaum, 1987; Platt, Kamphaus, Cole in Smith, 1991), kar potrjuje hipotezo o zmerno povezanih, a različnih konstruktih.

O višji povezavi med prilagoditvenimi spretnostmi in inteligentnostjo pa poročajo avtorji raziskav, v katere so bili vključeni posamezniki z motnjo $\mathrm{v}$ duševnem razvoju (Paskiewicz, 2009). Avtorja Vig in Jedrysek (1995), ki sta v svojo raziskavo vključila otroke $\mathrm{z}$ motnjo $\mathrm{v}$ duševnem razvoju, poročata o višji povezanosti med tema dvema področjema $(r=0,75)$. Ugotovila sta, da so povezave med posameznimi področji prilagoditvenih spretnosti in inteligentnostjo močnejše pri otrocih s težjimi motnjami (npr. avtistično motnjo) kot pri otrocih $\mathrm{z}$ manjšimi primanjkljaji (npr. s specifičnimi razvojnimi zaostanki, nizko povprečnimi intelektualnimi sposobnostmi).

\section{Prilagoditvene spretnosti pri posameznikih z avtizmom $^{3}$}

Številni avtorji (npr. Fenton idr., 2003; Gabriels, Ivers, Hill, Agnew in McNeill, 2007; Tomanik, Pearson, Loveland, Lane in Shaw, 2007) poročajo, da so prilagoditvene spretnosti pri posameznikih $\mathrm{z}$ avtizmom nižje, kot bi pričakovali glede na njihove spoznavne

\footnotetext{
${ }^{3}$ Izraz avtizem $\mathrm{v}$ članku označuje vse motnje avtističnega spektra.
} 
sposobnosti. Posamezniki $\mathrm{z}$ avtistično motnjo imajo glede na rezultate študij (npr. Gabriels idr., 2007; Perry, Flanagan, Dunn Geier in Freeman, 2009) v splošnem nižje prilagoditvene spretnosti kot njihovi vrstniki $\mathrm{z}$ enakimi intelektualnimi sposobnostmi, vendar brez avtizma. Nuovo in Buono (2007) prav tako poročata o nižjih prilagoditvenih spretnostih na vseh področjih pri skupini posameznikov $\mathrm{z}$ avtizmom s pridruženo motnjo $\mathrm{v}$ duševnem razvoju v primerjavi s skupinami posameznikov $\mathrm{z}$ motnjo v duševnem razvoju in shizofrenijo, z osebnostno motnjo, razpoloženjskimi motnjami, motnjo pozornosti s hiperaktivnostjo ali epilepsijo.

Avtorji raziskav o prilagoditvenih spretnostih pri posameznikih z avtizmom (npr. Bölte in Poustka, 2002; Kanne idr., 2011; Ray-Subramanian, Huai in Ellis Weismer, 2011) poročajo o pomembnih primanjkljajih na socialnem področju prilagoditvenih spretnostih. Tudi Volkmarovi študiji (Volkmar idr., 1987; Volkmar, Carter, Sparrow in Cicchetti, 1993), v katerih so preučevali prilagoditvene spretnosti pri otrocih $\mathrm{z}$ avtizmom s pomočjo Vinelandske lestvice prilagoditvenih spretnosti, poročata o specifičnem primanjkljaju na področju socialnih spretnosti v primerjavi z drugimi področji prilagoditvenih spretnosti pri otrocih $\mathrm{z}$ avtizmom.

Jacobson in Ackerman (1990) poročata o višjih vsakodnevnih spretnostih pri posameznikih z avtizmom $\mathrm{v}$ primerjavi $\mathrm{z}$ njihovimi vrstniki $\mathrm{z}$ motnjo $\mathrm{v}$ duševnem razvoju. Posamezniki $\mathrm{z}$ motnjo $\mathrm{v}$ duševnem razvoju, vključeni v njuno raziskavo, pa so dosegali višje rezultate pri socialnih spretnostih in govornih spretnostih kot njihovi vrstniki z avtizmom. O podobnem vzorcu prilagoditvenih spretnosti pri posameznikih $\mathrm{z}$ avtizmom poročata tudi Bölte in Poustka (2002) - v povprečju so njihove prilagoditvene spretnosti najvišje na področju praktičnih spretnosti, najnižje pa na področju komunikacije in socialnih spretnosti.

\section{Prilagoditvene spretnosti pri posameznikih z downovim sindromom}

Pri otrocih $\mathrm{z}$ downovim sindromom ne opazimo le razvojnega zaostanka, temveč tudi specifične vzorce funkcioniranja (Duijn, Dijkxhoorn, Scholte in BerckelaerOnnes, 2010). Avtorji (npr. Fidler, Hepburn in Rogers, 2006; Rodrique, Morgan in Gefiken, 1991) poročajo o relativno močnih socialnih spretnostih in samostojnosti ter o šibkejših gibalnih in komunikacijskih spretnostih. Dykens, Hodapp in Evans (2006) so v svoji raziskavi razvoja prilagoditvenih spretnosti pri otrocih $\mathrm{z}$ downovim sindromom ugotovili, da imajo ti otroci pomembno nižje komunikacijske spretnosti $\mathrm{v}$ primerjavi s praktičnimi in socializacijskimi spretnostmi. Rezultati te študije so pokazali, da imajo znotraj komunikacijskih spretnostih posebej težave pri govornem izražanju in ne toliko pri govornem razumevanju.

\section{Prilagoditvene spretnosti pri posameznikih z motnjo pozornosti s hiperaktivnostjo (attention deficit hyperactivity disorder - ADHD)}

Avtorji raziskav prilagoditvenih spretnosti pri posameznikih z ADHD konsistentno poročajo o njihovih nižjih prilagoditvenih spretnostih na vseh področjih (npr. Barkley, Fisher, Edelbrock in Smallish, 1990; Roizen, Blondis, Irwin in Stein, 1994; Stein, Szumowski, Blondis in Roizen, 1995). V teh študijah so ugotovili, da imajo otroci $\mathrm{z}$ ADHD pogosto nizkopovprečne ali mejne prilagoditvene spretnosti, kljub povprečnim spoznavnim sposobnostim. Čeprav tudi v raziskavah prilagoditvenih spretnosti pri otrocih $\mathrm{z}$ drugimi razvojnimi in psihiatričnimi motnjami poročajo o nižjih rezultatih, pa so razlike med spoznavnimi sposobnostmi in oceno prilagoditvenih spretnosti pri otrocih z ADHD večje kot pri drugih skupinah otrok (Stein idr., 1995). Razlika med spoznavnimi sposobnostmi in prilagoditvenimi spretnostmi pri otrocih z ADHD je tako velika, da so nekateri avtorji (npr. Roizen idr., 1994) predlagali, da bi pomembno razliko med spoznavnimi sposobnostmi in prilagoditvenimi spretnostmi obravnavali kot znak ADHD, ki so ga avtorji interpretirali kot možno posledico razlike med znanjem in resnično uporabo določene spretnosti v situaciji, ko je to potrebno.

Glede posameznih področij, avtorji poročajo o nižjih komunikacijskih, socialnih, praktičnih spretnostih in spretnostih samonadzora pri posameznikih z ADHD (Barkley, 2005; Stein idr., 1995; Wang, Huang in Lo, 2011). Tudi odrasli z ADHD imajo pogosto nižje prilagoditvene spretnosti predvsem na socialnem področju, na področju dela in akademskih spretnosti (Barkley, 2005).

\section{Ocenjevanje prilagoditvenih spretnosti}

Čeprav se ocenjevanje prilagoditvenih spretnosti tradicionalno povezuje $\mathrm{z}$ ocenjevanjem in razvrščanjem motnje $v$ duševnem razvoju, je koncept prilagoditvenih spretnosti pomemben za vse posameznike. Prilagoditvene spretnosti naj bi bile del standardne ocenjevalne baterije pri otrocih in odraslih, ki imajo različne težave, motnje ali manjše zmožnosti, povezane $\mathrm{z}$ njihovim vsakodnevnim funkcioniranjem (Harrison in Oakland, 2008). Ocenjevanje prilagoditvenih spretnosti nam lahko da pomembne informacije za ocenjevanje in načrtovanje obravnave pri posameznikih z razvojnim zaostankom, biološkimi dejavniki tveganja, avtizmom, motnjo pozornosti s hiperaktivnostjo, specifičnimi učnimi težavami, čustvenimi in vedenjskimi motnjami, motnjami senzorike, demenco, alzheimerjevo boleznijo, psihozo itd. (Harrison in Oakland, 2008). 
Pri ocenjevanju prilagoditvenih spretnosti nas zanima, kaj posameznik navadno počne, in ne, česa je sposoben. Zato je pomembno, da posameznikove prilagoditvene spretnosti ocenjuje nekdo, ki ga dobro pozna in z njim preživi veliko časa (npr. starši, vzgojiteljica, učitelj ...), saj le taka oseba pozna posameznikovo delovanje v različnih situacijah (Harman idr., 2010).

Za merjenje prilagoditvenih spretnosti uporabljamo različne standardizirane pripomočke (preizkuse, standardizirane intervjuje, ocenjevalne lestvice). Najpogosteje se za ocenjevanje prilagoditvenih spretnosti uporabljajo naslednji psihometrični pripomočki (povzeto po Carr, 2006):

- Lestvica prilagoditvenih spretnosti, druga izdaja (Adaptive behavior scale - second edition, ABS-II; Lambert, Nihira in Leyland, 1993)

Lestvica ABS-II je namenjena ocenjevanju prilagoditvenih spretnosti na šestnajstih področjih (npr. samostojno funkcioniranje, razvoj govora, odgovornost ...) in ocenjevanju težav $v$ vedenju (npr. nasilno vedenje, težave $\mathrm{v}$ socialnem vedenju ...). Lestvica ABS-II ima dve različici, in sicer je šolska namenjena ocenjevanju otrok od 3. do 18. leta, različica za odrasle pa je namenjena odraslim po 18. letu starosti.

- Vinelandska lestvica prilagoditvenih spretnosti, druga izdaja (Vineland adaptive behaviour scales - second edition, VABS-II; Sparrow, Cicchetti in Balla, 2005)

Z VABS-II ocenimo prilagoditvene spretnosti na štirih področjih: komunikacija, praktične spretnosti, socializacija in gibalne spretnosti. Vključuje tudi lestvico za oceno vedenjskih težav - težav ponotranjenja, težav pozunanjenja in drugih oblik motečega vedenja. Na voljo je oblika za starše in učitelje. Uporabljamo jo lahko pri otrocih od rojstva do 18. leta.

- Lestvica samostojnosti, prenovljena različica (Scales of independent behavior - revised, SIBR; Bruininks, Woodcock, Weatherman in Hill, 1996)

$\mathrm{Z}$ lestvico SIB-R lahko ocenimo prilagoditvene spretnosti na štirih področjih - gibanje, socialna interakcija in komunikacija, osebno življenje in življenje v širšem okolju. Vsebuje tudi 3 lestvice, s katerimi ocenjujemo vedenjske težave - težave ponotranjenja, težave pozunanjenja in težave $\mathrm{v}$ socialnem vedenju. Namenjena je ocenjevanju posameznikov od rojstva do 80 . let.

- Lestvice prilagoditvenih spretnosti, druga izdaja (Adaptive behaviour assessment system - second edition, ABAS-II; Harrison in Oakland, 2008)

Lestvice ABAS-II ocenjujejo 10 področij prilagoditvenih spretnosti, ki so vključene $\mathrm{v}$ opredelitev motnje $\mathrm{v}$ duševnem razvoju - komunikacija, vključevanje v širše okolje, funkcionalne predakademske spretnosti, življenje doma, zdravje in varnost, prosti čas, skrb zase, samonadzor, socializacija in gibanje. Posamezna področja prilagoditvenih spretnosti se povezujejo v tri širša področja - konceptualno, socialno in praktično. Namenjena je ocenjevanju posameznikovih prilagoditvenih spretnosti od rojstva do 89 . leta.

\section{Učenje prilagoditvenih spretnosti}

Vsi otroci se rodijo pripravljeni na učenje (Sorrels, 2012). Čeprav se prilagoditvenih spretnosti učijo vsi posamezniki, je bilo največ pozornosti in raziskav posvečeno prilagoditvenim spretnostim pri posameznikih $\mathrm{z}$ motnjo v duševnem razvoju (McCarver in Campbell, 1987). Predvsem za te je namreč zelo pomembno, da jih vse življenje učimo prilagoditvenih spretnosti, ki so bistvenega pomena za njihovo optimalno delovanje (Carr in O'Reilly, 2007). Izbor spretnosti, način in ritem učenja prilagoditvenih spretnosti pa morajo biti prilagojeni posameznikovi starosti in sposobnostim (Zetlin in Morrison, 1998).

V prvih dveh letih življenja je za zdrav razvoj in uspešno učenje bistvenega pomena, da je otrok varno navezan in hkrati avtonomen (Sorrels, 2012). Otroku prijazno okolje je tisto, v katerem se otroka spodbuja $\mathrm{k}$ čim samostojnejšemu opravljanju čim več nalog, saj tako razvija prilagoditvene spretnosti. Nizko nameščeni obešalniki za oblačila, hrana, ki se jo lahko je z rokami, pručka pri umivalniku in podobne prilagoditve so načini spodbujanja prilagoditvenih spretnosti in hkrati pomoč pri povečevanju otrokove samostojnosti (Sorrels, 2012). Pomembna za učinkovitejše učenje prilagoditvenih spretnosti sta tudi samouravnavanje vedenja (sposobnost nadzora čustev, vedenja in mišljenja) in dobre socialne spretnosti, saj sta oba koncepta povezana $\mathrm{Z}$ uspešnim učenjem (Sorrels, 2012). Spodbujanje razvoja samouravnavanja (npr. spodbujanje vztrajanja pri igri, pomoč otroku pri prepoznavanju in poimenovanju čustev) in socialnih spretnosti (npr. spodbujanje razvoja empatije, sodelovanje v socialnih igrah, igri z vrstniki) pomenita tudi spodbujanje razvoja prilagoditvenih spretnosti.

Zelo pomembne za pridobivanje prilagoditvenih spretnosti so izkušnje. Bolj kot so življenjske izkušnje otroka bogate in raznolike, bolj razvite bodo njegove prilagoditvene spretnosti. Ko na primer malček meče stvari z mize in opazuje, kako padejo na tla, se uči o gravitaciji. Zato je pomembno, da otroku omogočimo čim več različnih izkušenj, s katerimi se bo lahko učil in hkrati pridobival nove prilagoditvene spretnosti (Sorrels, 2012).

Vokviruučenjaprilagoditvenihspretnostisopomembni programi, s katerimi posameznike učimo praktičnih spretnosti - skrbi zase, aktivnosti v vsakodnevnem življenju, prilagoditve na delo (Carr in O'Reilly, 2007). Nekatere izmed tovrstnih tehnik, ki so se izkazale za izredno učinkovite pri učenju prilagoditvenih spretnosti, 
so tehnike uporabne analize vedenj (Applied Behavioral Analysis [ABA]). Ena od osnovnih idej uporabne analize vedenj je, da izbrano vedenje (npr. umivanje zob) najprej razdelimo na več posameznih dejanj, saj posameznik lažje usvoji posamezne korake kompleksne spretnosti in jih nato poveže v celoto (O’Reilly idr., 2007). Učenje posameznih korakov je sistematično, s pomočjo konkretnih navodil in pozitivnega podkrepljevanja. Pri učenju umivanja zob bi tako na primer najprej razdelili samo dejanje umivanja na več posameznih korakov (npr. 'Vzemi zobno ščetko in jo drži v roki. Zmoči zobno ščetko. Odstrani pokrovček zobne paste." itd.), podali bi konkretna navodila za izvedbo posameznega koraka (npr. v obliki sličic, ki bi jih nalepili nad lijak ali v obliki konkretnih verbalnih navodil 'Vzemi zobno pasto.') in pozitivno podkrepljevali ustrezno vedenje vsakič, ko se to pojavi (npr. besedna pohvala vsakič, ko posamezniku uspe stisniti zobno pasto na ščetko). Ko je naučena spretnost že utrjena, je lahko podkrepljevanja vedno manj, spodbuditi pa moramo uporabo naučene spretnosti v različnih situacijah oziroma okoljih in s tem generalizacijo naučene spretnosti (O’Reilly idr., 2007).

\section{Sklep}

Prilagoditvene spretnosti so konceptualne, socialne in praktične spretnosti, ki se jih ljudje naučimo, da bi lahko funkcionirali v vsakodnevnem življenju (AAIDD, 2012). Glede na merila DSM IV (1994) in AAIDD (Schaloc idr., 2010) je ocena prilagoditvenih spretnosti nujni del ocenjevanja motnje $v$ duševnem razvoju. Kljub temu da je ocenjevanje prilagoditvenih spretnosti $\mathrm{v}$ zadnjih letih vse večkrat vključeno $\mathrm{v}$ obravnavo in načrtovanje pomoči posameznikom $\mathrm{z}$ različnimi težavami, motnjami ali boleznimi, ki vplivajo na posameznikovo vsakodnevno funkcioniranje, to ni del rutinske prakse. Ocena prilagoditvenih spretnosti je pomembna za ocenjevanje posameznikove ravni samostojnosti in neodvisnosti, na osnovi katere oblikujemo načrt terapevtskega programa ali vzgojno-izobraževalne cilje, kot tudi za ugotavljanje napredka in merjenje učinkovitosti terapevtskih in vzgojno-izobraževalnih programov. Priporočljivo je, da ocena prilagoditvenih spretnosti predstavlja del celostne obravnave posameznikov $\mathrm{z}$ razvojnimi in drugimi motnjami.

\section{Literatura}

Ainsworth, M. D. S. in Bowlby, J. (1991). An ethological approach to personality development. American Psychologist, 46(4), 333-341. doi: 10.1037/0003-066X.46.4.333

Allen-Meares, P. (2008). Assessing the adaptive behavior of youths: Multicultural responsivity. Social Work, 53(4), 307-316.

Als, H., Butler, S., Kosta, S. in McAnulty, G. (2005). The assessment of preterm infants' behavior (APIB): Furthering the understanding and measurment of neurodevelopmental competence in preterm and fullterm infants. Mental Retardation and Developmental Disabilities Research Reviews, 11, 94-102.

American Association on Intellectual and Developmental Disabilities (AAIDD) (2012). Definition of intellectual disability. Pridobljeno na spletni strani http://www. aaidd.org/content_100.cfm?navID=21 dne 10.1.2012.

Barkley, R. A. (2005). Attention deficit hyperactivity disorder: A handbook for diagnosis and treatment (3. izd.). New York: The Guilford Press

Barkley, R. A., Fischer, M., Edelbrock, C. S. in Smallish, L. (1990). The adolescent outcome of hyperactive children diagnosed by research criteria: An 8-year prospective follow-up study. Journal of the American Academy of Child and Adolescent Psychiatry, 29(4), 546-557.

Bölte, S. in Poustka, F. (2002). The relation between general cognitive level and adaptive behavior domains in individuals with autism with and without co-morbid mental retardation. Child Psychiatry and Human Development, 33(2), 165-172.

Bornstein, M. H., Giusti, Z., Leach, D. B. in Venuti, P. (2005). Maternal reports of adaptive behaviours in young children: Urban-rural and gender comparisons in Italy and United States. Infant and Child Development, 14(4), 403-424.

Borthwick-Duffy, S. (2006). Adaptive behavior. V J. W. Jacobson, J. A. Mulick in J. Rojahn (ur.), Handbook of intellectual and developmental disabilities (str. 279-293). New York: Springer Science.

Carr, A. (2006). The handbook of child and adolescent clinical psychology: A contextual approach (2. izd.). London: Routledge.

Carr, A. in O'Reilly (2007). Lifespan development and the family lifecycle. V A. Carr, G. O'Reilly, P. Noonan Walsh in J. Mcevoy (ur.), The handbook of intellectual disability and clinical psychology practice (str. 5091). London: Routledge.

Child, I. L. (1954). Socialization. V L. Gardner (ur), Handbook of social psychology (str. 655-692). Oxford: Addison-Wesley Publishing Co.

Diagnostic and statistical manual of the mental disorders (4. izdaja - text revision, DSM-IV-TR) (1994). Washington, DC: APA.

Ditterline, J. in Oakland, T. (2009). Relationships between adaptive behavior and impairment. V S. Goldstain in J. A. Naglieri (ur.), Assessing impairment: From theory to practice (str. 31-49). New York: Springer publishing company. doi: 10.1007/978-1-387-87542-2

Duijn, G., Dijkxhoorn, Y., Scholte, E. M. in BerckelaerOnnes, I. A. (2010). The development of adaptive skills in young people with Down syndrome. Journal of Intellectual Disability Research, 45, 943-954.

Dykens, E. M., Hodapp, R. M. in Evans, D. (2006). Profiles and development of adaptive behavior in children with Down syndrome. Down's Syndrome, Research and Practice, 9(3), 45-50. doi: 10.3104/reprints.293

Fenton, G., D'Ardia, C., Valente, D., Vecchio, I. D., Fabrizi, A. in Bernabei, P. (2003). Vineland adaptive behavior 
profiles in children with autism and moderate to severe developmental delay. Autism, 7, 269-287. doi: 10.1177/1362361303007003004

Fidler, D. J., Hepburn, S. in Rogers, S. (2006). Early learning and adaptive behavior in toddlers with Down syndrome: Evidence for an emerging behavioral phenotype? Down Syndrome Research and Practice, 9(3), 37-44.

Gabriels, R. L., Ivers, B. J., Hill, D. E., Agnew, J. A. in McNeill, J. (2007). Stability of adaptive behaviors in middle-school children with autism spectrum disorders. Research in Autism Spectrum Disorders, 1, 291-303.

Harman, J. in Smith-Bonahue, T. (2010). The Bayley III Adaptive Behavior Scale. V Weiss, L. G., Oakland, T. in Alyward, G. (ur.), Bayley-III: Clinical use and interpretation (str. 177-200). London: Elsevier.

Harman, J. L., Smith-Bonahue, T. M. in Oakland, T. (2010). Assessment of adaptive behavior development in young children. V T. Oakland in E. Mpofu (ur.), Rehabilitation and Health Assessment: Applying ICF Guidelines (str. 333-352). New York: Springer.

Harrison, P. L. in Boan, C. H. (2000). Assessment of adaptive behavior. In B. A. Bracken (ur.), Psychoeducational assessment of preschool children (str. 124-144). Needham Heights, MA: Allyn \& Bacon.

Harrison, P. L. in Oakland, T. (2008). Adaptive behavior assessment system (2. izd.). Los Angeles: Western Psychological Services.

Jacobson, J. W. in Ackerman, L. (1990). Differences in adaptive functioning among people with autism or mental retardation. Journal of Autism and Developmental Disorders, 20(2), 205-219.

Kanne, S. M., Gerber, A. J., Quirmbach, L. M., Sparrow, S. S., Cicchetti, D. V. in Saulnier, C. A. (2011). The role of adaptive behavior in autism spectrum disorders: Implications for functional outcome. Journal of Autism and Developmental Disorders, 41(8), 10071018. doi: 10.1007/s10803-010-1126-4

Keith, T. Z., Fehrmann, P. G., Harrison, P. L. in Pottebaum, S. M. (1987). The relation between adaptive behavior and intelligence: Testing alternative explanations. Journal of School Psychology, 25, 31-43.

Kodrič, J. (2010). Psihološko ocenjevanje otrok z motnjo $v$ duševnem razvoju: 3 . posvet na temo usmerjanje otrok z Downovim sindromom - strokovno gradivo [Psychological assessment of children with intellectual disabilities: 3rd meeting concerning educational councelling for children with Down Syndrome - professional literature]. Ljubljana: Sožitje, Sekcija za Downov sindrom.

Luckasson, R., Borthwick-Duffy, S., Buntinx, W. H. E., Coulter, D. L., Craig, E. M., Reeve, ... Tasse, M. J. (2002). Mental retardation: Definition, classification, and systems of supports (10. izd.). Washington, DC: American Association on Mental Retardation.
McCarver, R. B. in Campbell, V. A. (1987). Future developments in the concept and application of adaptive behavior. The Journal of Special Education, 21(1), 197-207.

Mednarodna klasifikacija funkcioniranja, zmanjšne zmožnosti in zdravja - verzija za otroke in mladostnike: $M K F-O M$ (2008). Č. Marinček (ur.). Ljubljana: MZ RS, IVZ RS in IRSR.

Nuovo, S. F. in Buono, S. (2007). Psychiatric syndromes comorbid with mental retardation: Differences in cognitive and adaptive skills. Journal of Psychiatric Research, 41(9), 795-800.

O’Reilly, M., Sigafoos, J., Lancioni, G. E., Green, V. A., Olive, M. in Canella, H. (2007). Applied behavior analysis. V A. Carr, G. O'Reilly, P. Noonan Walsh in J. Mcevoy (ur.), The handbook of intellectual disability and clinical psychology practice (str. 253280). London: Routledge.

Paskiewicz, T. L. (2009). A comparison of adaptive behavior skills and IQ in three populations: Children with learning disabilities, mental retardation and autism (neobjavljena doktorska disertacija). Temple university, Philadelphia, Pennsylvania.

Perry, A., Flanagan, H. E., Dunn Geier, J. in Freeman, N. L. (2009). Brief report: Vineland adaptive behavior scales young children with autism spectrum disorders at different cognitive levels. Journal of Autism and Developmental Disorders, 39, 1066-1078. doi: 10.1007/s10803-009-0704-9

Platt, L. O., Kamphaus, R. W., Cole, R. W. in Smith, C. L. (1991). Relationship between adaptive behavior and intelligence: Aditional evidence. Psychological Reports, 68, 139-145.

Ray-Subramanian, C. E., Huai, N. in Ellis Weismer, S. (2011). Brief report: Adaptive behavior and cognitive skills for toddlers on the autism spectrum. Journal of Autism and Developmental Disorders, 41(5), 679684. doi: 10.1007/s10803-010-1083-y

Reva, K. K. in Bardos A. N. (2010). Assessing adaptive skills in a pediatric population. V A. Davis (ur.), The handbook of pediatric neuropsychology (str. 245249). New York: Springer.

Rodrique, J., Morgan, S. in Gefiken, G. (1991). A comparative evaluation of adaptive behavior in children and adolescents with autism, Down's syndrome and normal development. Journal of Autism and Developmental Disorders, 21, 187-196.

Roizen, N. J., Blondis T. A., Irwin, M. in Stein M. (1994). Adaptive functioning in children with attentiondeficit hyperactivity disorder. Archives of Pediatrics \& Adolescent Medicine, 148(11), 1137-1142.

Schalock, R. L., Borthwick-Duffy, S. A., Bradley, V. J.; Buntinx, W. H. E., Coulter, D. L., Craig, E. M., ... Yeager, M. H. (2010). Intellectual disability: Definition, classification, and systems of supports (11. izd.). Washington, DC: American Association of Intelectual and Developmental Disability. 
Sorrels, B. (2012). The foundations of learning framework - a model for school readiness. Journal of Zero to Three, 33(1), 10-16.

Sparrow, S. S., Cicchetti, D. V. in Balla, D. A. (2005). Vineland Adaptive Behavior Scales (2.izd.). Minneapolis, MN: Pearson Assessments.

Stein, M. A., Szumowski, E., Blondis, T. A. in Roizen, N. J. (1995). Adaptive skills dysfunction in ADD and ADHD children. Journal of Child Psychology and Psychiatry and Allied Disciplines, 36(4), 663-670. doi: 10.1111/1469-7610.ep11530170

Tassé, M. J. in Craig, E. M. (1999). Critical issues in the cross-cultural assessment of adaptive behaviour. V R. L. Schalock (ur.), Adaptive behaviour and its measurement: Implications for the field of mental retardation (str. 15-42). Washington, DC: American Association of Intellectual and Developmental Disability.

Taverna, L., Bornstein, M. H., Putnick, D. L. in Axia, G. (2011). Adaptive behaviors in young children: A unique cultural comparison in Italy. Journal of Cross-Cultural Psychology, 42(3), 445-465. doi: 10.1177/0022022110362748

Tomanik, S. S., Pearson, D. A., Loveland, K. A., Lane, D. M. in Shaw, J. B. (2007). Improving the reliability of autism diagnoses: Examining utility of adaptive behavior. Journal of Autism and Developmental Disorders, 37, 921-928.

Vig, S. in Jedrysek, E. (1995). Adaptive behavior of young urban children with developmental disabilities. Mental Retardation, 33(2), 90-98.

Volkmar, F. R., Sparrow, S., Goudreau, D., Cicchetti, D., Paul, R. in Cohen, D. (1987). Social deficits in autism: An operational approach using the Vineland Adaptive Behavior Scales. Journal of American Academy of Child and Adolescent Psychiatry, 26, 156-161.

Volkmar, F. R., Carter, A., Sparrow, S. in Cicchetti, D. (1993). Quantifying social development in autism. Journal of American Academy of Child and Adolescent Psychiatry, 32, 627-632.

Zetlin, A. in Morrison, G. (1998). Adaptation through the life span. V J. Burack, R. Hodapp in E. Zigler (ur.), Handbook of mental retardation and development (str. 481-503). Cambridge: Cambridge University Press.

Wang, H. Y., Huang, T. H. in Lo, S. K. (2011). Motor ability and adaptive function in children with attention deficit hyperactivity disorder. The Kaohsiung Journal of Medical Sciences, 27(10), 446-452. doi: 10.1016/j.kjms.2011.06.004 